\title{
Helicobacter pylori may induce bile reflux: link between $H$ pylori and bile induced injury to gastric epithelium
}

\author{
S D Ladas, J Katsogridakis, H Malamou, H Giannopoulou, M Kesse-Elia, S A Raptis
}

\begin{abstract}
Helicobacter pylori and duodenogastric reflux are both recognised as playing aetiological roles in chronic gastritis. This study investigated whether $H$ pylori colonisation of the antral mucosa and duodenogastric reflux are independent phenomena or have a causal relationship. Thirty eight patients (15 men, 23 women) aged (mean (SD)) 48 (17) years participated. Each patient underwent gastroscopy. Antral biopsy specimens were taken to investigate $H$ pylori colonisation. In addition BrIDA-99m Tc/ ${ }^{111} I n-$ DTPA scintigraphy was used to quantify duodenogastric reflux. $H$ pylori positive patients who were found to have duodenogastric reflux were treated with amoxycillin ( $1 \mathrm{~g} / \mathrm{d})$ and metronidazole (1.5 g/d) for seven days and four tablets of bismuth subcitrate daily for four weeks. Follow up antral biopsies and scintigraphy were repeated at six months. Duodenogastric reflux could not be found in 18 patients, including eight $(44 \%)$ who were $H$ pylori positive. Ten of the 11 patients who had duodenogastric reflux (reflux \% $11.6(9.2)$ ), however, were $H$ pylori positive $\left(\chi^{2}=6 \cdot 26, p=0 \cdot 01\right)$. These 10 patients were given eradication treatment. At six months, in six patients who became $H$ pylori negative, duodenogastric reflux was significantly reduced from a pretreatment value of $14 \cdot 3 \%$ to $3 \cdot 3 \%$ (two tail, paired $t=2 \cdot 57, p=0 \cdot 016$ ). These data suggest that $H$ pylori may induced duodenogastric reflux which may be important in the pathogenesis of $H$ pylori gastritis or carcinogenesis, or both.
\end{abstract} (Gut 1996; 38: 15-18)

Keywords: Helicobacter pylori, bile reflux, duodenogastric reflux, $H$ pylori gastritis, gastric carcinogenesis.

Helicobacter pylori infection of the gastric mucosa is regarded as the major aetiological agent in chronic diffuse, superficial gastritis ${ }^{12}$ and an important risk factor for the development of intestinal type gastric carcinoma, ${ }^{3}$ though other factors, such as duodenogastric reflux (DGR) of bile, may play a part. ${ }^{4}$ It has long been accepted that bile reflux affects the gastric mucosa ${ }^{5}$ and is now regarded as an important cause of reactive gastritis. ${ }^{47}$ However, published reports investigating a possible relationship between bile reflux and $H$ pylori colonisation of the antral mucosa or $H$ pylori gastritis, or both, have given conflicting results. ${ }^{8-15} \mathrm{We}$ therefore investigated whether $H$ pylori colonisation of the antral mucosa and DGR of bile are independent phenomena or whether there is a causal relationship. This hypothesis was tested by measuring DGR before and after successful $H$ pylori eradication in patients with intact stomachs.

\section{Patients and methods}

\section{PATIENTS}

Thirty eight patients, 15 men and 23 women aged mean (SD) 48 (17) years, participated in this prospective study. Ten patients had uncomplicated duodenal ulcer, two with second degree oesophagitis, and 26 had nonulcer dyspepsia. No patient had had any abdominal surgery or known chronic liver disease. Women of child bearing age were not included in the study. The patients were informed about the nature of the study and all 38 agreed to participate. The protocol of the study was approved by the Ethical Committee on Human Studies, Department of Internal Medicine, University of Athens, in February 1992.

\section{METHODS}

\section{Study design}

On admission to the study each patient underwent upper gastrointestinal endoscopy and three antral mucosal biopsy specimens were taken from the lesser curve for a rapid urease test (CLO-test, Delta West, Bentley, Western Australia) and Gram stain biopsy smears. Patients in whom the results of the CLO-test and Gram staining were in agreement had $99 \mathrm{~m}$ Technetium-3-bromo2,4,6-trimethylimino-diacetic acid/ ${ }^{111}$ Indiumdiethylenetriamine pentacetate (BrIDA$\left.{ }^{99} \mathrm{mTc} /{ }^{111} \mathrm{In}-\mathrm{DTPA}\right)$ scintigraphy to quantify DGR. Those patients with both DGR and $H$ pylori colonisation of the antral mucosa were treated with triple $H$ pylori eradication therapy including $1 \mathrm{~g}$ amoxycillin and $1.5 \mathrm{~g}$ metronidazole daily for seven days and four tablets of colloidal bismuth subcitrate (De-Nol) daily, for four weeks. Similar triple therapy regimens are reported to have a $H$ pylori eradication efficacy of between 72 and $90 \%$. $^{1617}$ At six months, all treated patients had follow up 


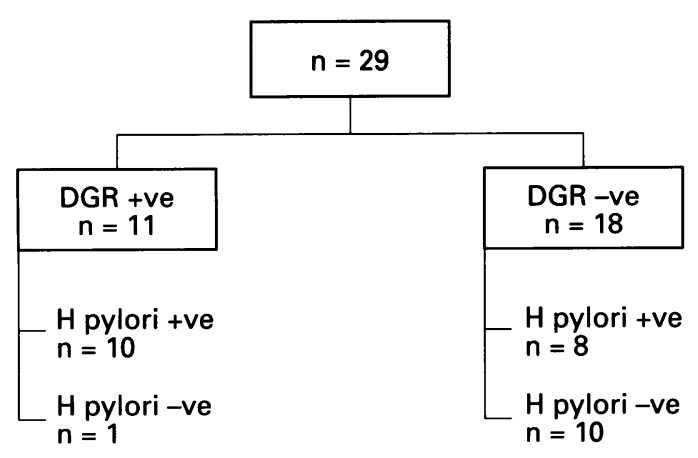

Figure 1: Of the 38 patients admitted to the study, nine were excluded because a reliable estimation of duodenogastric reflux (DGR) was not possible in two and in seven the CLO-test and Gram staining results did not agree. The 29 remaining patients had $B r I D A-99 \mathrm{~m} T c^{111}$ In$D T P A$ scan to quantify DGR. Significantly more patients with $D G R(D G R+v e)$ were $\mathrm{H}$ pylori positive compared with patients without $D G R\left(\chi^{2}=6 \cdot 26, d f=1, p=0 \cdot 012\right)$

gastroscopy and antral biopsy specimens were taken to assess $H$ pylori colonisation status. In those who became $H$ pylori negative, BrIDA${ }^{99 \mathrm{~m}} \mathrm{Tc} /{ }^{111} \mathrm{In}-\mathrm{DTPA}$ scintigraphy was repeated to quantify DGR.

\section{Detection of $\mathrm{H}$ pylori}

Both a rapid urease test and Gram staining were used to identify $H$ pylori colonisation of the antral mucosa. One antral biopsy specimen was immersed in the yellow gel of the rapid urease test and gel colour change to pink (positive test) was checked for every 15 minutes over a two hour period. The CLO-test has a specificity of $97 \%$, a sensitivity of about $95 \%$, and gives a positive result at two hours in more than $80 \%$ of $H$ pylori colonised patients. ${ }^{18}$ 19 Each of the remaining biopsy specimens $(n=2)$ was crushed between two microscope slides, thereby producing four biopsy smears. All four smears were Gram stained and evaluated by an experienced bacteriologist (HM) for the presence and colonisation density of spiral bacteria, which appeared as red curved bacilli on Gram stain. The bacteriologist was 'blinded' to the results of the CLO test. Colonisation density was scored from one $(<10)$ to four $(>50$ bacteria in at least one power field). $H$ pylori positive patients were defined as those positive for both tests. Where the results of the tests did not agree, the patient was withdrawn from the study.

\section{$B r I D A-99 \mathrm{~m} T{ }^{1{ }^{11}}$ In-DTPA scintigraphy}

DGR was assessed by two senior staff (HG and MK-E) of the Nuclear Medicine Department, who were 'blinded' to the $H$ pylori colonisation status of each patient.

After an overnight fast the patient received intravenously $2 \mathrm{mCi}$ of BrIDA- ${ }^{-9} \mathrm{~m} \mathrm{Tc}$, which is cleared selectively by the hepatocyte via the same pathway as bilirubin. Thirty minutes later, the patient was placed semirecumbent under a large field of view gammacamera (with a medium energy collimator) to obtain a baseline image. He then received a semi-liquid meal, consisting of two egg yolks beaten with $20 \mathrm{~g}$ of sugar, and drank $200 \mathrm{ml}$ of water labelled with $100 \mu \mathrm{Ci}$ of ${ }^{111}$ In-DTPA to delineate the gastric area of interest. Images of the abdomen were then acquired simultaneously in two windows $\left({ }^{99 \mathrm{~m} T \mathrm{Tc} \text { and }}{ }^{111} \mathrm{In}\right)$ every five minutes for the next hour. The DGR index was calculated according to the formula $D G R=\left(S_{t}-S_{o}\right) /\left(H_{o}-H_{t}\right) \cdot 100$, where $S_{t}$ and $S_{o}$ are ${ }^{99 \mathrm{~m}} \mathrm{Tc}$-BrIDA activities over the stomach region at times $t$ (max gastric activity) and zero (baseline image) respectively, whereas $H_{t}$ and $\mathrm{H}_{\mathrm{o}}$ are ${ }^{99 \mathrm{~m}}$ Tc-BrIDA activities over the hepatobiliary region at times $t$ and zero respectively. The results were corrected for radioactive decay and blood background. BrIDA${ }^{99} \mathrm{~m} \mathrm{Tc} /{ }^{111} \mathrm{In}$-DTPA scintigraphy is the only non-invasive method available to quantitate DGR. The results of this method correlate highly with the actual concentration of bile acids recovered from the stomach. ${ }^{20}$

\section{Statistical analysis}

All data are presented as mean (SD). The statistical significance of the results was assessed by the $\chi^{2}$ test with continuity correction factor or paired two tailed $t$ test and regression analysis as appropriate. ${ }^{21} \mathrm{~A} p$ value of less than 0.05 was regarded significant.

\section{Results}

Nine of the 38 patients admitted to the study (Fig 1) were excluded. In two of these patients superimposed jejunal loops on the gastric antrum did not allow a reliable estimate of DGR. In seven patients there was no agreement between the results of the CLO-test and Gram staining. Six of them had a positive CLO-test, but the Gram stain was negative. One additional patient had a negative CLOtest but the Gram stain was positive for $H$ pylori-like bacteria. In the remaining 29 patients (Table), both the CLO-test and Gram stain were negative in 11 and positive in 18 . Eleven patients were therefore defined as $H$ pylori negative and 18 as $H$ pylori positive.

In 18 of the 29 patients no DGR could be shown, but the remaining 11 patients had a mean (SD) DGR score of $11.6(9.2) \%$. When combining the results of $H$ pylori colonisation with those of DGR, $10(91 \%)$ of the 11 patients who had DGR were found to be colonised by $H$ pylori, but only $8(44 \%)$ of those did not have DGR $(\mathrm{n}=18)$ were $H$ pylori positive $\left(\chi^{2}=6 \cdot 26, d f=1, p=0 \cdot 012\right)$. There was no correlation between the DGR score and the density of $H$ pylori colonisation $(\mathrm{r}=0.02$, $\mathrm{p}=0 \cdot 7$, nor was the density of colonisation different in patients with $(n=10)$ and without reflux $(n=9)\left(\chi^{2}=0 \cdot 3, d f=2, p=0 \cdot 9\right)$.

All $10 \mathrm{H}$ pylori positive patients who had DGR underwent treatment to eradicate $H$ pylori. One was lost to follow up at six months. Follow up endoscopy with biopsies showed that three of the nine patients were still colonised by $H$ pylori, but six patients became $H$ pylori negative (Table). After successful $H$ pylori eradication treatment in the six patients, the DGR score was significantly reduced (Fig 2) from a pretreatment mean 
TABLE I Clinical data, Helicobacter pylori colonisation status of the gastric mucosa and results of duodenogastric reflux (DGR) measurements of the patients studied

\begin{tabular}{|c|c|c|c|c|c|c|c|}
\hline No & Sex & $\begin{array}{l}\text { Age } \\
(y)\end{array}$ & Diagnosis & $\begin{array}{l}\text { H pylori } \\
\text { colonisation }\end{array}$ & $\begin{array}{l}\text { 1st } D G R^{\star} \\
(\%)\end{array}$ & $\begin{array}{l}\text { Post eradication } \\
\text { H pylori status }\end{array}$ & $\begin{array}{l}\text { 2nd DGR } \\
(\%)\end{array}$ \\
\hline 1 & $\mathbf{M}$ & 26 & DU & + & 3 & - & 2 \\
\hline 2 & M & 27 & OES & + & 13 & - & 3 \\
\hline 3 & $\mathrm{~F}$ & 50 & $\mathrm{DU}$ & + & 22 & - & 5 \\
\hline 4 & $\mathrm{~F}$ & 63 & NUD & + & 10 & - & 0 \\
\hline 5 & $\mathbf{M}$ & 30 & DU & + & 6 & - & 0 \\
\hline 6 & $\mathrm{~F}$ & 65 & NUD & + & 32 & - & 10 \\
\hline 7 & $\mathbf{M}$ & 34 & NUD & + & 11 & + & ND \\
\hline 8 & $\mathrm{~F}$ & 41 & NUD & + & 4 & + & ND \\
\hline 9 & $\mathrm{~F}$ & 56 & NUD & + & 3 & Lost & Lost \\
\hline 10 & $\mathrm{~F}$ & 47 & DU & + & 12 & + & ND \\
\hline 11 & $\mathrm{~F}$ & 42 & NUD & - & 3 & NFUP & NFUP \\
\hline 12 & $\mathbf{F}$ & 67 & NUD & - & 0 & NFUP & NFUP \\
\hline 13 & F & 42 & NUD & - & 0 & NFUP & NFUP \\
\hline 14 & $\mathbf{M}$ & 31 & NUD & - & 0 & NFUP & NFUP \\
\hline 15 & $\mathbf{M}$ & 32 & DU & - & 0 & NFUP & NFUP \\
\hline 16 & $\mathrm{~F}$ & 60 & NUD & - & 0 & NFUP & NFUP \\
\hline 17 & $\mathrm{~F}$ & 43 & NUD & - & 0 & NFUP & NFUP \\
\hline 18 & $\mathbf{F}$ & 68 & NUD & - & 0 & NFUP & NFUP \\
\hline 19 & F & 43 & NUD & - & 0 & NFUP & NFUP \\
\hline 20 & $\mathbf{F}$ & 62 & NUD & - & 0 & NFUP & NFUP \\
\hline 21 & M & 58 & DU & - & 0 & NFUP & NFUP \\
\hline 22 & M & 28 & DU & + & 0 & NFUP & NFUP \\
\hline 23 & $\mathbf{M}$ & 72 & OES & + & 0 & NFUP & NFUP \\
\hline 24 & M & 34 & DU & + & 0 & NFUP & NFUP \\
\hline 25 & $\mathrm{~F}$ & 73 & NUD & + & 0 & NFUP & NFUP \\
\hline 26 & $\mathbf{M}$ & 69 & DU & + & 0 & NFUP & NFUP \\
\hline 27 & M & 64 & DU & + & 0 & NFUP & NFUP \\
\hline 28 & $\mathrm{~F}$ & 40 & NUD & + & 0 & NFUP & NFUP \\
\hline 29 & $\mathbf{M}$ & 35 & NUD & + & 0 & NFUP & NFUP \\
\hline
\end{tabular}

$\mathrm{DU}=$ duodenal ulcer, $\mathrm{NUD}=$ non ulcer dyspepsia, $\mathrm{OES}=$ oesophagitis, $\mathrm{ND}=$ not done, NFUP $=$ no follow up, Lost $=$ lost to follow up.

* 1 st DGR = before treatment; 2nd DGR=after treatment.

value of $14.3(10.9)$ to $3.3(3.8) \%$ (two tailed pair $t$ test $=2 \cdot 57, \mathrm{p}=0 \cdot 016)$.

\section{Discussion}

It has long been accepted that the gastric mucosal barrier can be damaged by factors such as ingestion of aspirin and non-steroidal anti-inflammatory drugs, and by bile reflux. Bile acids and lysolecithin, were regarded as important factors in the pathogenesis of chronic gastritis and peptic ulcer. ${ }^{22}{ }^{23}$ During the past 10 years, however, these theories have been superseded by evidence indicating that chronic $H$ pylori infection of the gastric mucosa is related to chronic gastritis ${ }^{24} 25$ and duodenal ulcer $^{2627}$ and is a risk factor for gastric carcinogenesis. $^{3}$

Though $H$ pylori and bile reflux gastritis are regarded as district histopathological entities, a number of studies have attempted to explain a possible relationship between $H$ pylori gastritis and DGR of bile. Thus, it has been shown that bile is hostile to $H$ pylori colonisation in vitro. ${ }^{9}$ 1228 The effect of bile reflux on $H$ pylor colonisation of the gastric mucosa has also

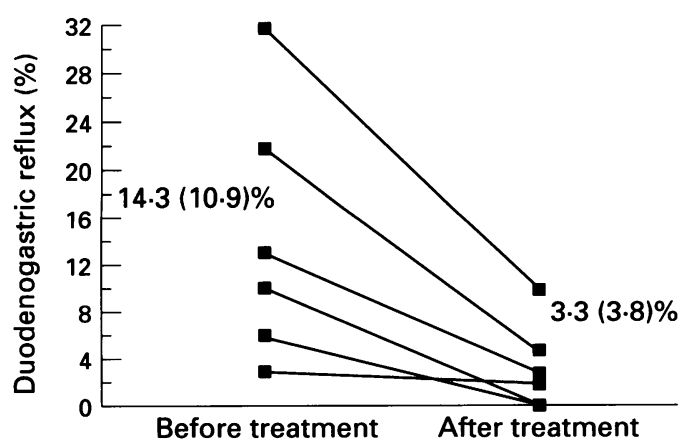

Figure 2: After successful Helicobacter pylori eradication treatment duodenogastric reflux was significantly reduced in all six patients (two tailed paired $\mathrm{t}=2 \cdot 57, \mathrm{p}=0 \cdot 016$ ). been investigated in patients who have undergone gastric surgery. In one of these studies no significant difference could be shown in the quantity of bile reflux between $H$ pylori positive and negative patients, ${ }^{29}$ but two other studies came to the conclusion that postoperative bile reflux may play a role in the eradication of $H$ pylori. ${ }^{811}$ Furthermore, it has been shown that $H$ pylori recolonises the mucosa of the gastric remnant after bile diversion (Rouxen-Y anastomosis). ${ }^{30} 31$ Despite these observations, it seems that in the intact stomach bile reflux and $H$ pylori often coexist ${ }^{4} 10$ and both may therefore be involved in the pathogenesis of gastritis. This is because the bile acid concentrations of gastric aspirates sampled from patients who have not undergone surgery are usually much lower than those used in the in vitro studies ${ }^{91228}$ and those measured in postoperative stomachs. ${ }^{3031}$ The results of our study not only confirm that $H$ pylori may survive the noxious effect of bile reflux in the intact stomach, but also that significantly more $H$ pylori positive patients than $H$ pylori negative patients may have DGR. We could not, however, show any significant correlation between the DGR score and the density of $H$ pylori colonisation of the gastric mucosa, probably because of the patchy distribution of $H$ pylori colonisation, which may result in tissue sampling error.

The association between $H$ pylori colonisation of the gastric mucosa and DGR was further investigated by comparing DGR before and six months after successful $H$ pylori eradication. A long post treatment period was thought to be necessary for restoration of the gastric physiology after successful $H$ pylori eradication. Though many investigators suggest that successful $H$ pylori eradication is evident if $H$ pylori can no longer be detected four weeks after the end of antimicrobial therapy, this length of time has been selected arbitrarily and most recurrences occur within six months, indicating that they may not be true recurrences but actually the result of incomplete $H$ pylori eradication. Our observation that DGR is consistently reduced after successful $H$ pylori eradication, implies that $H$ pylori may actually be involved in the pathogenesis of DGR. This may be explained when considering that $H$ pylori gastritis may alter gastric physiology by reducing the number of somatostatin producing cells of the gastric mucosa, ${ }^{32}$ and by increasing both basal and meal stimulated gastrin release. ${ }^{33}$ The increase of serum gastrin may affect antroduodenal motility and may be implicated in the pathophysiology of DGR. ${ }^{34}$

One limitation of this study is that we have investigated only postprandial DGR over a short period, while it is not known whether fasting or postprandial DGR is the more important and whether they coexist in the same patient. Certainly, a comparison of 24 hour DGR recording in $H$ pylori positive and negative patients may provide us with more relevant information.

The importance of DGR as a cause of bile reflux induced gastritis and even of gastric 
cancer is well recognised. Our data suggest that $H$ pylori may induce DGR and therefore both may act synergistically on the gastric mucosa inducing chronic gastritis, which may lead to the carcinoma sequence. Indeed, it has recently been shown that the prevalence of intestinal metaplasia is greatest in those patients who have both $H$ pylori associated gastritis and high intragastric bile acid concentration. ${ }^{4}$

1 Morris A, Nicholson G. Ingestion of Campylobacter pylorides causes gastritis and raised fasting gastric pH. $\mathrm{Am}$ pylorides causes gastritis and raised

2 Blaser MJ. Hypothesis on the pathogenesis and natural history of Helicobacter pylori-induced inflammation. Gastroenterology 1992; 102: 720-7.

3 Parsonnet J, Friedman GD, Vandersteen DP. Helicobacter pylori infection and the risk of gastric carcinoma. $N$ Engl $\mathcal{F}$ Med 1991; 325: 1127-31

4 Sobala GM, O'Connor HJ, Dewar EP, King RFG, Axon ATR, Dixon MF. Bile reflux and intestinal metaplasia in gastric mucosa. I Clin Pathol 1993; 46: 235-40.

5 Eastwood GL. Effect pH on bile salt injury to mouse gastric mucosa. Gastroenterology 1975; 69: 591-7.

6 Houghton PWJ, Mortensen NJMcC, Thomas WEG, Cooper MJ, Morgan AP, Burton P. Intragastric bile acids Cooper MJ, Morgan AP, Burton P. Intragastric bile acids
and histological changes in gastric mucosa. Br $f$ Surg and histological

7 Dixon MF, O'Connor HJ, Axon ATR, King RFJG, Johnston D. Reflux gastritis: distinct histopathological entity? f Clin Pathol 1986; 39: 524-30.

8 O'Connor HJ, Wyatt J, Dixon MF, Axon ATR. Campylobacter like organisms and reflux gastritis. $\mathcal{f}$ Clin Pathol 1986; 39: 531-4.

9 Tompkins DS, West AP. H pylori, acid and bile. 7 Clin Pathol 1987; 40: 1387 .

10 Karttunen T, Niemela S. Campylobacter pylori and duodenogastric reflux in peptic ulcer disease and gastritis. denogastric reflux in

11 Offerhaus GJA, Rieu PNMA, Jansen JBMJ, Joosten HJM, Lamers CBHW. Prospective comparative study of the influence of postoperative bile reflux on gastric mucosal histology and Campylobacter pylori infection. Gut 1989; 30: 1552-7.

12 Mathai E, Arora A, Cafferkey M, Keane CT, O'Morain C. The effect of bile acids on the growth and adherence of Helicobacter pylori. Aliment Pharmacol Therap 1991; 5: 653-68.

13 Mitchell HM, Li Y, Hu P, Hazell SL, Du G, Byrne DJ, et al. The susceptibility of Helicobacter pylori to bile may be an obstacle to faecal transmission. Eur 7 Gastroenterol Hepatol 1992; 4 (suppl 1): S79-83.

14 Stein HJ, Smyrk TC, DeMeester TR, Rouse J, Hinder RA. Clinical value of endoscopy and histology in the diagnosis of duodenc

15 Scalon P, DiMario F, Del Favero G, Meggiato T, Rugge M Baffa $\mathbf{R}$, et al. Biochemical and histopathological aspects in duodenogastric reflux gastritis patients with or without prior cholecystectomy. Acta Gastroenterol Belg 1993; 56: 215-8.

16 Lambert JR, Lin SK, Schembri M, Nicholson L, Korman MG. Helicobacter pylori therapy randomized study of DeNol/antibiotic combinations. Rev Esp Enferm Dig 1990; 78 (suppl 1): 115-6 (abstract)

17 Logan RPH, Gummett PA, Misiewicz J, Karim QN, Walker MM, Baron JH. One week eradication regimen fo Helicobacter pylori. Lancet 1991; 338: 1249-52.

18 Marshall BJ, Warren JR, Francis GJ, Langton SR, Goodwin CS, Blincow ED. Rapid urease test in the management of Campylobacter pyloridis-associated gastritis. $A m \mathcal{f}$ Gastroenterol 1987; 82: 200-10.

19 McNulty CAM, Dent JC, Off JC, Gear MWL, Wilkinson SP. Detection of Campylobacter pylori by the biopsy urease test: an assessment in 1445 patients. Gut 1989; 30 1058-62.

20 Nicolai J, Silberbusch J, van Roon F, Schopman WVD, Berg JWD. A simple method for quantification of biliary Berg JW. Acand $f$ Gastroenterol 1980; 15: 775-80.

21 Armit. $\mathrm{P}$ Berry G. Statistical methods in medical research. 2nd ed. London: Blackwell, 1987.

22 Rhodes J, Bernardo DE, Phillips SF, Rovelstad RA, Hofmann AF. Increased reflux of bile into the stomach in patients with gastric ulcer. Gastroenterology 1969; 57: 241-52.

23 Johnson AG, McDermott SJ. Lysolecithin: a factor in the pathogenesis of gastric ulceration? Gut 1974; 15: 710-3.

24 Dooley CP, Fitzgibbons PL, Cohen H, Appleman MD, Perez-Perez GI, Blaster MJ. Prevalence of Helicobacter pylori infection and histologic gastritis in asymptomatic persons. N Engl f Med 1989; 321: 1562-6.

25 Blaser MJ. Helicobacter pylori and the pathogenesis of gastroduodenal inflammation. F Infect Dis 1990; 161: gastrodu.

26 Hosking SW, Ling KW, Chung SCS, Yung MY, Cheng FB, Sung JJY, et al. Duodenal ulcer healing by eradication of Helicobacter pylori without anti-acid treatment: randomized controlled trial. Lancet 1994; 343: 508-10.

27 Logan RPH, Gummett PA, Misiewicz J, Karim QN, Walker MM, Baron JH. One week's anti-Helicobacte pylori treatment for duodenal ulcer. Gut 1994; 35: 15-8.

28 Hanninen ML. Sensitivity of Helicobacter pylori to different bile salts. Eur f Clin Microbiol Infect Dis 1991; 10: 518-8.

29 Robles-Campos R, Lujan-Mompean JA, Parrilla-Paricio $P$ Bermejo-Lopez J, Lizon-Ruiz R, Torralba-Martinez JA, $e t$ al. Role of Helicobacter pylori infection and duode-nogastric reflux gastritis after gastric operations. Surg Gynecol tric reflux gastritis after

30 Loffeld RJL, Loffeld BCA, Arends JW, Flendrig JA, Van Spreeuwel JP. Retrospective study of Campylobacter-like organisms in patients undergoing partial gastrectomy. $\mathcal{f}$ Clin Pathol 1988; 41: 1313-5.

31 O'Connor HJ, Newbold KN, Alexander-Williams J, Thompson H, Drumm J, Donovan IA. Effect of Roux-en$Y$ biliary diversion on Campylobacter pylori. Gastroenterology 1989; 97: 958-64.

32 Moss SF, Legon S, Bishop AE, Polak JM, Calam J. Effect of Helicobacter pylori on gastric somatostatin in duodenal ulcer disease Lancet 1992; 340: 930-2.

33 Levi S, Beardshall K, Playford R, Ghosh P, Haddad G Calam J. Campylobacter pylori and duodenal ulcer: the gastrin link. Lancet 1989; i: 1167-8.

34 Calam J, Tracy HJ. Pyloric reflux and G-cell hyperfunction. Lancet 1980; ii: 918. 